\title{
Nuevas Alternativas de Aprender y Enseñar: \\ Aprendizaje cooperativo.
}

Beatriz Ordóñez Cervantes*

beaoc62@hotmail.com

Ramón Ferreiro Gravié

Trillas, 2007

El libro completa la trilogía publicada por el autor sobre un tema de suma importancia para todos los actores implicados en la educación, abordando una de las innovaciones educativas más comentadas de los últimos tiempos:

La tercera obra continúa desarrollando la tesis de la trascendencia pedagógica del trabajo cooperativo de los educandos en pequeños grupos en la construcción del conocimiento y en el desarrollo del pensamiento crítico y creativo. Asimismo, destaca la importancia de las habilidades sociales que favorecen la madurez (inteligencia emocional) necesaria para todo buen desempeño, así como para educar en valores.

El autor es profesor de educación de Nova Southeastern University en Estados Unidos pero es coordinador de los proyectos y programas que la escuela tiene en diversos países latinoamericanos.

La obra va dirigida a todos los profesionales de la educación y a los capacitadores, si bien es cierto que el tema no es abordado de manera exhaustiva se convierte en un marco de referencia bien fundamentado científicamente y aporta sugerencias prácticas que como señala el propio autor son derivadas no sólo de investigaciones experimentales y de acción-participación, sino también de la observación y documentaciones de las mejores prácticas de maestros que han sido capacitados en cientos de escuelas y universidades públicas y privadas en diversos países de Latinoamérica.

En el mundo globalizado que nos ha tocado vivir tenemos todos conocimiento de que las nuevas tecnologías pueden informar, el reto está en que además constituyan un medio para formar a las nuevas generaciones como ciudadanos con los valores que demanda la sociedad democrática que todos estamos empeñados en construir para nuestros países. 
El doctor Ferreiro, presidente de la Red Latinoamericana Talento, presenta distintas formas posibles de organizar el proceso de enseñanza, alternativas educativas que, puestas en práctica a partir de los principios, las funciones y de las estrategias para cada uno de los momentos del aprendizaje cooperativo, hacen posible el desarrollo del pensamiento crítico y creativo de los educandos, en otras palabras, estimulan el desarrollo de la inteligencia y la creatividad de los niños, adolescentes y jóvenes, induciendo modos valiosos de conductas sociales.

Para introducir el contenido del libro es importante situar el tema del aprendizaje cooperativo como eje de todo el texto. El autor con sus más de veinte años de investigaciones sobre el tema plantea que en primer lugar la categoría básica del aprendizaje cooperativo es la interdependencia que se logra a partir de las relaciones de cooperación entre los implicados en el aprendizaje. Ello no implica suprimir el trabajo individual; es necesario prepararse mejor para el esfuerzo grupal, con objeto de sacar entre todos una tarea. Cooperar es compartir una experiencia vital significativa que exige trabajar juntos para lograr beneficios mutuos. La cooperación implica resultados en conjunto, mediante una interdependencia positiva que involucra a todos los miembros del equipo en lo que se hace y en cuyo proceso cada uno aporta un talento.

Lo antes planteado no es espontáneo: hay que enseñar a cooperar en la práctica diaria del salón de clases. Aprendizaje cooperativo es una metodología que establece cómo agrupar a los educandos en el salón de clases, cuántos alumnos por equipo, la forma de disponer el mobiliario. Así como las funciones didácticas que van a cumplimentarse y las estrategias que hacen posible la mediación en cada momento de la lección, entre otros aspectos para que los alumnos aprendan significativamente.

Se requiere de modo explícito desarrollar un conjunto de habilidades sociales y actitudes que poco a poco los alumnos interioricen y hagan suyas, habilidades y actitudes que favorezcan las relaciones interpersonales e incidan en el desarrollo personal de todos y cada uno, en lo intelectual y también en lo socioafectivo.

Es una realidad conocida por todos que en nuestra sociedad contemporánea, la presencia de las tecnologías de la información y las telecomunicaciones está cambiando la organización y dinámica de muchas instituciones, entre otras la escuela. A los niños, adolescentes y jóvenes que asisten a las instituciones educativas les pertenecen, por generación, esas tecnologías.

Prácticamente toda innovación educativa de hoy día se plantea de una u otra forma, el empleo de las llamadas nuevas tecnologías de la educación, y del aprendizaje cooperativo. Más aún la integración de ambos para la creación de 
entornos diferentes de enseñanza centrados en el educando, éstos son introducidos en el primer capítulo del libro bajo el título de "nuevos ambientes de aprendizaje". Los nuevos ambientes de aprendizaje implican contar con una concepción de aprendizaje y también de enseñanza de manera que, a partir de un modelo educativo explícito, puedan emplearse alternativas didácticas que hagan posible que las tecnologías de la educación, además de informar, formen a las nuevas generaciones.

Con la presente obra el autor consigue de manera, clara, ordenada y muy accesible presentar el concepto de nuevos ambientes de aprendizaje. Sugerir el empleo de "nuevas" alternativas didácticas (entre ellas, el estudio de casos, la solución de problemas y la realización de proyectos), como parte de la creación de entornos diferentes de enseñanza, y a partir de la aplicación del aprendizaje cooperativo, ya que sólo así cada una de ellas puede realmente contribuir al desarrollo de los educandos.

El libro está organizado en 14 capítulos dedicados a un número igual de alternativas didácticas que bien pueden ser aplicadas en sí mismas, o bien como metodología de los nuevos ambientes de aprendizaje. A partir del capítulo tres empiezan las alternativas didácticas. La posibilidad de ponerse a prueba: la solución de problemas. El futuro previsible: el método de proyectos. La realidad social en el aula: el método del caso. La personalización necesaria: el método del contrato. La aplicación del método científico: la investigación en grupo. La integración de lo sensorial y lo racional: la observación triádica. La confrontación necesaria: el seminario. El intercambio fructífero: el coloquio. La posibilidad de ser otro y seguir siendo uno: la simulación didáctica. El valor de las vivencias: el taller. La sistematización de la experiencia: la ponencia científica. Entre cada una de las novedosas alternativas hay diferencias, pero también puntos de coincidencia, en el empleo exitoso de cada una de las anteriores alternativas radica, entro otros factores en la aplicación de la didáctica del aprendizaje cooperativo.

Cada uno de los capítulos -en palabras del autor- sigue el orden de exposición de las "cinco felices comadres", es decir aquél que nos responde a las preguntas en qué consiste, por qué, para qué, cómo, y cuándo y dónde, lo que facilita, entre otras cosas, la posible comparación entre las distintas alternativas didácticas. Resulta un ejercicio interesante que cada lector pueda ordenar en función de su lógica a las distintas comadres según su estilo de aprendizaje y por tanto hacer su propia lectura de cada capítulo. Según los expertos todos tenemos una "comadre" favorita, aquélla que, si no la contestamos, no llegamos a comprender significativamente el contenido de aprendizaje. Esta estrategia contribuye sin duda a desarrollar el pensamiento lógico de los lectores (de los alumnos) así como su 
pensamiento creativo ya que el nivel de comprensión es mayor cuando estamos en condiciones de ver nuevas aristas de un asunto.

Al final de cada capítulo, en la sección llamada "sugerencias para seguir aprendiendo", mediante la orientación de distintas actividades se estimula la construcción del conocimiento.

La lectura del libro resulta enriquecedora para alumnos y maestros de las licenciaturas en Pedagogía y Ciencias de la Educación; es un hecho que la fundamentación científica que aporta el constructivismo y el empleo de la didáctica del aprendizaje cooperativo constituyen la base teórico-práctica para el correcto empleo de las nuevas tecnologías de la educación.

El objetivo es ambicioso y muy noble: hacer que las nuevas tecnologías coadyuven en la formación personal y profesional que exige la sociedad contemporánea, cuyo problema central, más que de conocimientos es de valores y de ética. Estas alternativas didácticas posibilitan la actividad formativa de los educandos, de su forma de pensar, sentir y actuar.

Recomiendo ampliamente la lectura de la obra a mi modo de ver una respuesta puntual a lo que demanda la educación del siglo XXI, un buen aliado en la difícil pero apasionante tarea de formar lo más valioso de la persona humana: su inteligencia y creatividad, sus afectos y virtudes. 